\title{
Immune recovery among HIV-infected patients in northwestern Tanzania after 2 years of anti-retroviral therapy use: a retrospective cohort study
}

BONAVENTURA C.T. MPONDO', RODRICK KABANGILA ${ }^{2,3}$, LUCHERI EPHRAIM ${ }^{2,3}$, ALEX ERNEST $^{4}$ and BENSON R. KIDENYA $5^{*}$

${ }^{1}$ Department of Internal Medicine, University of Dodoma, Dodoma, Tanzania

${ }^{2}$ Department of Internal Medicine, Catholic University of Health and Allied Sciences, Mwanza, Tanzania

${ }^{3}$ Department of Internal Medicine, Bugando Medical Centre, Mwanza, Tanzania

${ }^{4}$ Department of Obstetrics and Gynaecology, University of Dodoma, Dodoma, Tanzania

${ }^{5}$ Department of Biochemistry and Molecular Biology, Catholic University of Health and Allied Sciences, Mwanza, Tanzania

\begin{abstract}
Background: The use of antiretroviral therapy (ART) for the treatment of human immunodeficiency virus (HIV) is associated with significant and sustained decrease in the viral RNA levels that allows the immune system to recover. The extent of this immune recovery depends on the baseline CD4 count. Evidence on the extent of immune recovery in patients with advanced HIV from resource limited settings is scarce. The objective of this study was to determine immune recovery in a cohort of HIV infected outpatients after using ART for a period of 2 years

Methods: This retrospective cohort study was conducted in an outpatient HIV clinic at Bugando Medical Centre in northwestern Tanzania. CD4+ T-cell counts for HIV-positive adults at the time of enrolment were measured and retrospectively followed up during ART eligibility screening process prior to initiation of antiretroviral (ARV) drugs. We then compared the CD4+ T-cell counts at baseline and that during the enrolment.

Results: A total of 238 patients files were screened for enrolment. Of the 238 patients, 171 (71.8\%) fulfilled the criteria and were enrolled for the study. The lack of participation was due to death 17 (7.1\%), lost to follow-up $32(13.4 \%)$ and refusal 18 (9.5\%). Of the 171 patients, the median CD4 count at the time of ART initiation was 153 cells/ $\mu$ l [Interquartile range (IQR): 78 - 199], 164 (95.9\%) had increased their CD4 cells count, with $74.3 \%$ having an increase of more than 150 cells/ $\mu$ l. Only 8 (4.7\%) patients had a decline of CD4 cell count. The median CD4 cells count after a 2-year follow up was significantly higher (396 [IQR: 295 - 567]) than at baseline (153 [IQR: 78 - 199]) cells/ul; p-value $<0.0001$ ).

Conclusion: The CD4 cells count increased significantly after a follow up period of 2 years after ART use in this cohort. Early diagnosis and ART initiation could therefore improve outcomes in HIV-infected patients in resource limited settings.

Keywords: HIV, antiretroviral therapy, Immune recovery, Tanzania
\end{abstract}

\section{Introduction}

HIV infection if untreated usually causes impaired immune function that is normally characterized by declining number of CD4 T-lymphocytes leading to increased susceptibility to opportunistic infections (Phillips et al., 1992). The correct use of antiretroviral (ARV) drugs significantly reduces viral load resulting in reduced morbidity and mortality among HIVinfected patients (Egger et al., 2002; Edwards et al., 2015). Studies have shown that prolonged viral suppression is associated with substantial increases in CD4 cell counts and reduction in the rates of opportunistic infections associated morbidity and mortality

\footnotetext{
Correspondence E-mail: benkidenya@yahoo.com
} 
(Battegay et al., 2006; Wabe \& Alemu, 2012). Such immune recovery has been shown to be partial consisting of an initial rapid recovery of CD4 T lymphocytes as well as improvement in their function (García et al., 2004; Moore \& Keruly, 2007; Zhou et al., 2010). After using antiretroviral therapy (ART) for 2-4 years, the mean (or median) CD4 gain is approximately between 200-300cells/ $\mu$ (Kaufmann et al., 2002; Smith et al., 2003). However, the rate of CD4 gain has been shown to diminish over time (García et al., 2004; Moore \& Keruly, 2007).

Very few patients who are on ART fail to reach a CD4 cell count of $>200$ cells $/ \mu$ l, a threshold below which most of the opportunistic infections occurs (Egger et al., 2002). The rate of $\mathrm{CD}_{4}$ gain is dependent on the baseline CD4 count, with those initiating therapy at lower CD4 counts ( $\leq 200$ cells/ $\mu$ l) as the case in most Sub-Saharan countries taking longer to achieve significant gains (Garciá et al., 2004; Egger et al., 2009; Robbins et al., 2009). Maximum immune recovery has been shown to occur when there is prolonged and successful viral suppression in patients using ART (Hejdeman et al., 20012; Edwards et al., 2015).

Several factors have been found to influence CD4 response. Several studies have described the association between the baseline CD4 and immune response (Verheggen, 2003; Nash et al., 2008). Patients initiating ART at very low CD4 count have been found to have poor immunological outcomes at follow up (García et al., 2004). Younger patients have also been shown to have better immune response compared to elderly patients (Cuzin et al., 2007; Kanters et al., 2014). This could be explained by reduced thymic function and $T$ cell replicative senescence with age (Kalayjian et al., 2003).

Very few studies have assessed immune recovery following ART use. Most of these studies have been done in developed countries where ART is initiated at relatively high CD4 count. Data on immune recovery in patients with advanced HIV in Tanzania is scarce. Availability of these data will be helpful in tailoring effective management of HIV infected patients on ART. Therefore, we conducted a study to determine immune recovery in a cohort of HIV infected outpatients after using ART for a period of 2 years.

\section{Materials and Methods}

\section{Study design and participants}

This was a retrospective cohort study conducted between August 2011 and April 2012 at Bugando Medical Centre (BMC) in Mwanza, northwestern Tanzania. BMC is the referral hospital for 13 million people in northwestern Tanzania. The hospital is located along the shore of lake Victoria, a region with the prevalence of HIV estimated to be over $6 \%$. The care and treatment clinic of BMC has a total of approximately 3500 patients 2700 of whom are on ART. We enrolled adult patients aged 18 years and above who visited BMC HIV clinic and initiated ART between September 2009 and February 2010; and measured their CD4+ T-cell count. Critically ill patients and patients with concurrent infections were excluded from the study.

\section{Data collection and laboratory analyses}

A structured questionnaire was used to collect demographic information. Baseline data (at the time of ART initiation) including CD4+ T-cell count (CD4 count) and body mass index (BMI) were obtained retrospectively from the HIV clinic database. During data collection (August 2011 - April 2012), same measurements were repeated using the same reagents and laboratory instruments that were used for the measurements at the time of ART initiation (September 2009 - February 2010). 


\section{Data analysis}

Continuous variables were summarized using medians with interquartile ranges [IQRs] and categorical variables were summarized using frequency and percentage. The outcome of interest was increment in CD4 cell count. CD4 cell counts at baseline and at the end of follow up (after 2 years of ART use) were paired. Wilcoxon signed-rank test was used to compare the significance of the difference in median CD4 counts. The statistical significance was set at 0.05 level. Data were analyzed using Stata version 12 (College Station, Texas).

\section{Ethical considerations}

Patients were provided with informed and written consent to participate in this study. This study was approved by the BMC Institutional Review Board.

\section{Results}

\section{Patients' characteristics}

A total of 238 patients were screened at the time of ART initiation. Of the 238 patients, 17 (7.1\%) had died and 32 (13.4\%) were lost to follow-up. Therefore, a total of 189 (79.4\%) patients were still actively attending CTC during the study period. However, of these 18 (9.5\%) did not provide informed consent for participation and hence 171 patients were eligible for this study. Among the 171 patients eligible for study, the median age was 39.1 [IQR, 33.8 - 44.2] years and about $70.8 \%$ (121) were female. Over $80 \%$ (150/171) of patients had either a primary level of education or lower, and over $80 \%$ (137/171) were either unemployed or self employed. Approximately two-thirds (96/171) of patients lived with their partners (either married or cohabiting). The most common ART regimens used were zidovudine/lamivudine/efavirenz (31\%; 53/171) followed by zidovudine/lamivudine/nevirapine (24\%; 41/171) (Table 1).

Table 1: Demographic and baseline data for 171 HIV-infected patients followed up for 2 years

\begin{tabular}{|c|c|c|c|}
\hline Patient characteristics & Response & Number/Median & $(\%)[\mathrm{IQR}]$ \\
\hline Age & & 39.1 & {$[33.8-44.2]$} \\
\hline \multirow[t]{2}{*}{ Sex } & Male & 50 & $(29.2)$ \\
\hline & Female & 121 & $(70.8)$ \\
\hline \multirow[t]{4}{*}{ Education } & None & 37 & $(21.6)$ \\
\hline & Primary & 113 & $(66.1)$ \\
\hline & Secondary & 15 & $(8.8)^{\prime}$ \\
\hline & College & 6 & (3.6) \\
\hline \multirow[t]{2}{*}{ Occupation } & Unemployed & 137 & $(80.1)$ \\
\hline & Employed & 34 & $(19.9)$ \\
\hline \multirow[t]{2}{*}{ Marital status } & Single & 75 & $(43.9)$ \\
\hline & $\begin{array}{l}\text { Married/Living with a } \\
\text { partner }\end{array}$ & 96 & $(56.1)$ \\
\hline 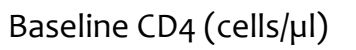 & & 153 & [78-199] \\
\hline Baseline BMI $\left(\mathrm{kg} / \mathrm{m}^{2}\right)$ & & 21.0 & {$[19-24]$} \\
\hline \multirow[t]{5}{*}{ ART regimen } & $\mathrm{AZT} / 3 \mathrm{TC} / \mathrm{EFV}$ & 53 & $(31.0)$ \\
\hline & $\mathrm{D} 4 \mathrm{~T} / 3 \mathrm{TC} / \mathrm{NVP}$ & 35 & (20.5) \\
\hline & $\mathrm{AZT} / 3 \mathrm{TC} / \mathrm{NVP}$ & 41 & $(24.0)$ \\
\hline & TDF/FTC/EFV & 40 & $(23.4)$ \\
\hline & TDF/FTC/NVP & 2 & $(1.2)$ \\
\hline
\end{tabular}




\section{Immune recovery}

Of the 171 patients, 163 (95.3\%) had an increment (positive change) in their CD4 cells count, with $74.3 \%$ having an increase of more than 150 cells/ $\mu$ l. The median CD4 cells count after a 2year follow up was significant higher than it was at baseline (396 [Interquartile range (IQR):

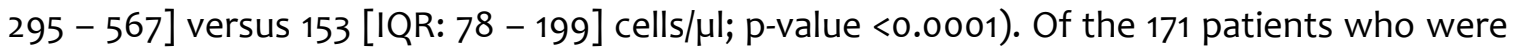
still actively attending CTC and consented to participate in the follow up study, 36 patients had a CD4 rise between $0-150$ cells/ $\mu$ l, majority had a rise of CD4 between 151 and 300 (66 patients (38.6\%). Sixty-one patients (35.7\%) had a CD4 rise of $>300$ cells $/ \mu$ l. Only $8(4.7 \%)$ patients had a decline of CD4 cell count (Table 2).

Table 2: Post treatment immune status outcome in $171 \mathrm{HIV}$-infected patients followed up for 2-years

\begin{tabular}{|c|c|c|}
\hline 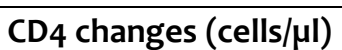 & Number & Percent (\%) \\
\hline Decrease & 8 & 4.7 \\
\hline $0-150$ & 36 & 21.0 \\
\hline $151-300$ & 66 & 38.6 \\
\hline$>300$ & 61 & 35.7 \\
\hline
\end{tabular}

\section{Discussion}

In this retrospective cohort study, there was substantial gain in CD4 T-cells after using ART for a median of two years. The median CD4 cells count after a 2-year follow up was significant higher than it was at baseline with only about $5 \%$ of the patients having a decline on their levels of CD4 cells. The reason for $\mathrm{CD}_{4}$ decline in 8 patients could not therefore be established. The median CD4 cell count at follow up was slightly higher compared with other previous studies (Kaufmann et al., 2002; Garciá et al., 2004). However, our findings are consistent with the study done elsewhere (Notermans et al., 1999; Kauffman et al. 2005). The findings of our study are consistent with previous studies that showed significant recovery of CD4 T lymphocytes within 2 years following ART use (Tarwater et al., 2001; Kaufmann et al., 2002; Wabe \& Alem, 2012).

Research findings indicate that moderate to severe immunodeficiency at baseline impair the long term immune recovery (Egger et al., 2009). Our patients had a median CD4 cell count below 200 cells/ $\mu$ l but were followed up for only two years, a period which has been shown to be significantly associated with CD4 gain as was observed in this cohort. Many studies with longer duration have shown significant immune recovery in the first two years, with no significant immune reconstitution thereafter especially in those with very low nadir CD4 cell counts (Kaufmann et al., 2000; Moore \& Keruly, 2007).

Some limitations for this study include a relatively smaller sample size. The follow up period was also relatively short to be able to study immune recovery trend. There are very few studies in sub-Saharan Africa, and to the best of our knowledge none in Tanzania that report on the immune recovery trends in HIV patients who are on ART. Viral load was not tested in this study.

In conclusion, majority of patients in Tanzania as in many other resource limited settings are diagnosed with HIV at very low CD4 counts. However initiation of ARV helps to restore immune status in majority of them within the first two years after ART initiation as found in this cohort. Early diagnosis and ART initiation would improve immunological outcome in HIV-infected patients in resource limited settings. We recommend studies to 
determine factors associated with CD4 T cells recovery among HIV infected patients initiated on ART.

\section{Acknowledgements}

We thank the Department of Internal Medicine and Counselling and Testing Centre of Bugando Medical Centre for their support throughout the study. We also thank all the patients who participated in this study. This study received financial support from the United States National Institutes of Health Fogarty International Center (TW 00018) and Pfizer Inc.

\section{Author contributions}

$B M, R K$ conceived and designed the experiments, BM, LE performed the experiments; BM, RK, BRK, AE analyzed the data and all the authors wrote the manuscript.

\section{References}

Battegay, M., Nüesch, R., Hirschel, B. \& Kaufmann, G.R. (2006) Immunological recovery and antiretroviral therapy inHIV-1 infection. Lancet Infectious Diseases 6, 280-287.

Cuzin, L., Delpierre, C., Gerard, S., Massip, P. \& Marchou, B. (2007) Immunologic and clinical responses to highly active antiretroviral therapy in patients with HIV infection aged $>50$ years. Clinical Infectious Diseases 45, 654-657.

Edwards, J.K., Cole, S. R., Martin, J., Moore, R., Mathews, W. C., Kitahata, M. \& Mugavero, M. J. (2015) Dynamic visual display of treatment response in HIV-infected adults. Clinical Infectious Diseases 61 (1): 1 1-4

Egger, M., May, M., Chêne, G., Phillips, A. N., Ledergerber, B., Dabis, F. \& Sterne, J.A.C. (2002) Prognosis of HIV-1-infected patients starting highly active antiretroviral therapy: a collaborative analysis of prospective studies. Lancet 360(9327), 119-129.

Egger, S., Petoumenos, K., Kamarulzaman, A., Hoy, J., Sungkanuparph, S., Chuah, J. \& Law, M.G. (2009) Long-term patterns in CD4 response are determined by an interaction between baseline CD4 cell count, viral load, and time: The Asia Pacific HIV Observational Database (APHOD). Journal of Acquired Immune Deficiency Syndromes 50, 513-520.

García, F., de Lazzari, E., Plana, M., Castro, P., Mestre, G., Nomdedeu, M. \& Gatell, J.M. (2004) Long-term CD4+ T-cell response to highly active antiretroviral therapy according to baseline CD4+ T-cell count. Journal of Acquired Immune Deficiency Syndromes 36, 702713.

Hejdeman, B., Lenkei, R., Leandersson, A.-C., Hultström, A.L., Wahren, B., Sandström, E. \& Bratt, G. (2001) Clinical and immunological benefits from highly active antiretroviral therapy in spite of limited viral load reduction in HIV type 1 infection. AIDS Research and Human Retroviruses 17, 277-286.

Kalayjian, R.C., Landay, A., Pollard, R.B., Taub, D.D., Gross, B.H., Francis, I.R. \& Lederman, M.M. (2003) Age-related immune dysfunction in health and in human immunodeficiency virus (HIV) disease: association of age and HIV infection with naive CD8+ cell depletion, reduced expression of CD28 on CD8+ cells, and reduced thymic volumes. Journal of Infectious Diseases 187, 1924-1933.

Kanters, S., Nachega, J., Funk, A., Mukasa, B., Montaner, J.S.G., Ford, N. \& Mills, E.J. (2014) CD4(+) T-cell recovery after initiation of antiretroviral therapy in a resource-limited setting: a prospective cohort analysis. Antiviral Therapy 19, 31-39. 
Kaufmann, G.R., Bloch, M., Finlayson, R., Zaunders, J., Smith, D. \& Cooper, D.A. (2002) The extent of HIV-1-related immunodeficiency and age predict the long-term CD4 T lymphocyte response to potent antiretroviral therapy. AIDS 16, 359-367.

Kaufmann, G.R., Bloch, M., Zaunders, J.J., Smith, D. \& Cooper, D.A. (2000) Long-term immunological response in HIV-1-infected subjects receiving potent antiretroviral therapy. AIDS 14, 959-969.

Kaufmann, G.R., Furrer, H., Ledergerber, B., Perrin, L., Opravil, M., Vernazza, P. \& Battegay, M. (2005) Characteristics, determinants, and clinical relevance of CD4 T cell recovery to $<500$ cells/microl in HIV type 1-infected individuals receiving potent antiretroviral therapy. Clinical Infectious Diseases 41, 361-372.

Moore, R.D., \& Keruly, J.C. (2007) CD4+ cell count 6 years after commencement of highly active antiretroviral therapy in persons with sustained virologic suppression. Clinical Infectious Diseases 44, 441-446.

Nash, D., Katyal, M., Brinkhof, M.W.G., Keiser, O., May, M., Hughes, R. \& Egger, M. (2008) Long-term immunologic response to antiretroviral therapy in low-income countries: a collaborative analysis of prospective studies. AIDS 22, 2291-302.

Notermans, D.W., Pakker, N.G., Hamann, D., Foudraine, N.A., Kauffmann, R.H., Meenhorst, P. L., \& Danner, S.A. (1999) Immune reconstitution after 2 years of successful potent antiretroviral therapy in previously untreated human immunodeficiency virus type 1infected adults. Journal of Infectious Diseases 180, 1050-1056.

Phillips, A.N., Lee, C.A., Elford, J., Janossy, G. \& Kernoff, P. B. (1992) The cumulative risk of AIDS as the CD4 lymphocyte count declines. Journal of Acquired Immune Deficiency Syndromes 5, 148-152.

Robbins, G.K., Spritzler, J.G., Chan, E.S., Asmuth, D.M., Gandhi, R.T., Rodriguez, B.A. \& Pollard, R.B. (2009) Incomplete reconstitution of $\mathrm{T}$ cell subsets on combination antiretroviral therapy in the AIDS Clinical Trials Group Protocol 384. Clinical Infectious Diseases 48, 350-361.

Smith, C.J., Sabin, C.A., Lampe, F.C., Kinloch-de-Loes, S., Gumley, H., Carroll, A. \& Phillips, A.N. (2003) The potential for CD4 cell increases in HIV-positive individuals who control viraemia with highly active antiretroviral therapy. AIDS 17, 963-969.

Tarwater, P.M., Margolick, J.B., Jin, J., Phair, J.P., Detels, R., Rinaldo, C. \& Muñoz, A. (2001) Increase and plateau of CD4 T-cell counts in the 3(1/2) years after initiation of potent antiretroviral therapy. Journal of Acquired Immune Deficiency Syndromes 27, 168-175.

Verheggen, R. (2003) Immune restoration in patients with HIV infection: HAART and beyond. Journal of the Association of Nurses in AIDS Care 14, 76-82.

Wabe, N. \& Alemu, M. (2012) Immunological and clinical progress of HIV-infected patients on highly active antiretroviral therapy in north west Ethiopia. Gaziantep Medical Journal 18, 1.

Zhou, J., Sirisanthana, T., Kiertiburanakul, S., Chen, Y.-M.A., Han, N., Lim, P.L. \& Law, M.G. (2010) Trends in CD4 counts in HIV-infected patients with HIV viral load monitoring while on combination antiretroviral treatment: results from The TREAT Asia HIV Observational Database. BMC Infectious Diseases 10(1): 361. 